\title{
Early Fetal Echocardiography
}

\author{
${ }^{1}$ Carmina Comas, ${ }^{2}$ Pilar Prats
}

\section{ABSTRACT}

Within the last decade, two significant events have contributed to the increasing interest in early fetal echocardiography. First, the introduction of high-frequency vaginal ultrasound probes allows detailed visualization of cardiac structures at early stage of gestation, making early detection of fetal malformations possible. Second, the close relationship observed between some first trimester sonographic and Doppler markers and congenital heart defects allows an early identification of a high-risk group at 11 to 14 weeks of gestation. In this context, from the early 1990s, many authors have examined the potential role of the transvaginal (TV) approach to obtain earlier diagnosis of fetal cardiac malformations. Further studies have appeared in the literature showing that early TV echocardiography in experienced hands is a fairly sensitive investigative tool. Although some malformations are detected as early as 11 weeks gestation, the optimal gestational age to perform the early scan is at least 13 weeks gestation. Transvaginal ultrasound is the preferred approach, although most of the authors agree that results can be improved if transabdominal ultrasound is also incorporated. The further application of color Doppler enhances visualization. The sensitivity and specificity of early fetal echocardiography for the detection of heart anomalies is acceptable compared with the ones obtained by midgestational echocardiography, showing a slight reduction in detection rates and an increase in false-positive and false-negative rates. The cardiac anomalies detected at this early stage of pregnancy are mainly defects involving the four-chamber view, indicating that defects solely affecting the outflow tracts are difficult to diagnose in the first trimester of pregnancy. Heart defects diagnosed early in pregnancy tend to be more complex than those detected later, with a higher incidence of associated structural malformations, chromosomal abnormalities, and spontaneous abortions. The neonate follow-up or postmortem examination in case of termination of pregnancy is essential to assess the actual role of early fetal echocardiography. At present, early fetal echocardiography is a promising technique, which can be of considerable value for patients at high risk. This technique is, however, currently limited to a few specialized centers.

The aim of this review is to explore the possibilities of examining the fetal heart at this early stage of pregnancy. This article also presents our experience in the first multicenter trial in early fetal echocardiography performed in Spain. In accordance with other studies, this experience stresses the usefulness of early echocardiography when performed by expert operators on fetus specifically at risk for cardiac defects. Our review of these additional 48 cases contributes to the expanding literature on the ability of TV ultrasonography to detect fetal heart defects in early pregnancy.

\footnotetext{
${ }^{1}$ Chief, ${ }^{2}$ Specialist

${ }^{1}$ Department of Obstetrics and Gynecology, Hospital Universitari Germans Trias i Pujol. Badalona (Spain)

${ }^{2}$ C.G.O. Centre Ginecològic i Obstètric. Mataró (Spain)

Corresponding Author: Carmina Comas, Chief, Department of Obstetrics and Gynecology, Hospital Universitari Germans Trias i Pujol. Badalona (Spain), Phone: +91-934978923 (ext. 8923) e-mail: minacomas.germanstrias@gencat.cat
}

Keywords: Congenital heart defects, Doppler, Fetal echocardiography, Transvaginal scan.

How to cite this article: Comas C, Prats P. Early Fetal Echocardiography. Donald School J Ultrasound Obstet Gynecol 2017;11(1):29-43.

\section{Source of support: Nil}

\section{Conflict of interest: None}

\section{INTRODUCTION}

Prenatal detection of fetal congenital heart disease (CHD) remains the most problematic issue of prenatal diagnosis. ${ }^{1}$ Major CHDs are the most common severe congenital malformations, with an incidence of about five in a thousand live births, whenever complete ascertainment is done and minor lesions are excluded. ${ }^{1,2}$ Congenital heart anomalies have a significant effect on affected children's life with up to 25 to $35 \%$ mortality rate during pregnancy and the postnatal period, and it is during the first year of life, when $60 \%$ of this mortality occurs. Moreover, major CHDs are responsible for nearly $50 \%$ of all neonatal and infant deaths due to congenital anomalies, and it is likely to be significantly higher if spontaneous abortions are considered. Although CHD used to appear isolated, they are frequently associated with other defects, chromosomal anomalies, and genetic syndromes. Their incidence is six times greater than chromosomal abnormalities and four times greater than neural tube defects. ${ }^{1-3}$

Most major CHDs can be diagnosed prenatally by detailed transabdominal second trimester echocardiography at 20 to 22 weeks gestation. ${ }^{1,3-6}$ The identification of pregnancies at high risk for CHD needing referral to specialist centers is of paramount importance in order to reduce the rate of overlooked defects. ${ }^{6,7}$ However, the main problem in prenatal diagnosis of CHD is that the majority of cases take place in pregnancies with no identifiable risk factors. Therefore, there is wide agreement that cardiac ultrasound screening should be introduced as an integral part of the routine scan at 20 to 22 weeks. When applied to low-risk population, scrutiny of the four-chamber view allows only the detection of $40 \%$ of the anomalies, while additional visualization of the outflow tracts and the great arteries increases the rate up to 60 to $70 \%$. $^{3-5}$

Recently, the findings of an increased nuchal translucency $(\mathrm{NT})^{8,9}$ or an altered ductus venosus (DV) blood flow $^{10,11}$ at 10 to 14 weeks' gestation have been associated 
with a high risk for $\mathrm{CHD}$, and their prevalence increases exponentially with the thickness of $\mathrm{NT}^{8}$ regardless of the fetal karyotype. Since earlier diagnosis of congenital malformations is increasingly demanded, the option of an early fetal echocardiography must be taken into account. ${ }^{12-14}$ The use of high-frequency vaginal ultrasound probes along with substantial improvements in magnification and processing of the imaging, together with the introduction of color Doppler, have extensively contributed to the development of the technique, allowing better visualization of cardiac structures earlier in pregnancy. ${ }^{12,15,16}$ Although most of the groups perform early fetal echocardiography between 13 and 16 weeks' gestation, we can name it as so when performed before the 18th week of gestation. Despite several studies that stated that fetal heart examination could be incorporated in first or early second trimester examinations, its use is currently still limited to a few specialized centers.

\section{TECHNICAL ISSUES}

Regarding early fetal echocardiography, some institutions predominantly use the transvaginal (TV) approach, ${ }^{14,17-22}$ while others prefer the transabdominal one. ${ }^{23-26}$ Most of the authors reporting early fetal echocardiography prefer the TV approach due to its increased resolution associated with higher frequency transducers and also because given the equivalent transducers frequencies, the TV probes provide better quality images. ${ }^{27}$ However, most importantly, authors with background training as pediatric cardiologists are more likely to use the transabdominal approach in contrast with most of obstetricians, who are well used to the TV route. The superiority of TV sonography is usually well accepted before the 14th week. Between the 15th and 18th weeks, both transabdominal and TV routes seem to offer similar advantages and disadvantages, and beyond the 18th week, the transabdominal echocardiography seems to achieve better results. 1,5,16,27,28

The combination of two-dimensional (2D) echocardiography with color Doppler flow imaging proved generally helpful, in particular, by visualization of blood flow on both great arteries and of two divided ventricular inflows. The addition of color Doppler flow studies provides substantial improvement in the diagnostic accuracy of early echocardiography, as was also shown by DeVore ${ }^{29}$ for transabdominal sonography in the second half of pregnancy.

When performing early fetal echocardiography, we firstly recommend scanning by the TV route, following the examination by the transabdominal probe when a complete study is not possible. The highest frequency must always be used, whatever the route is chosen. Obviously, a high-resolution real-time ultrasound has to be used. For color Doppler evaluation, the energy output levels have to be lower than $50 \mathrm{~mW} / \mathrm{cm}^{2}$ spatial peak-temporal average. Since color Doppler is dissipated over a wide area of interest, thermal effects resulting from Doppler insonation should not be a matter of concern, unlike pulsed Doppler in which the whole energy of the beam is focused at a specific location. Besides, the embryonic development of the heart has been completed by the time the scan is performed.

\section{ULTRASOUND ANATOMY OF THE NORMAL HEART}

Embryonic heartbeat can be detected as early as the 5 th week of gestation, and normal development of its function shows an increasing heart rate from 80 to 90 beats per minute at 5 weeks' gestation to 170 to 180 beats per minute at the end of the 9th to 10th week. As pregnancy progresses, the control of the heart rate matures with increasing vagal dominance, and the baseline rate declines to 145 to 155 beats per minute with the appearance of beat-to-beat variation, most likely resulting from the functional adaptation to the development of the heart and autonomic nervous system maturation, and remains more or less constant during the rest of intrauterine life. ${ }^{30,31}$

The structural development of the heart begins on day 16, and it is finished by the 10th week. Early fetal echocardiography has the same goals as that of the standard one and we advocate to perform it in a segmental approach. The first objective of the examination is to assess the normality of the four-chamber view through a transverse section of the fetal chest: Normal situs solitus; normal size and axis of the heart in relation to the chest; both atria equal in size, with the foramen ovale flapping within the left atrium; both ventricles equal in size and contractility; atrial and ventricular septa of normal appearance; and tricuspid and mitral valves normally inserted, opening and closing together. Color and pulsed Doppler are particularly useful to confirm normal inflow to the ventricles and to detect turbulent flow or jets, suggesting valve regurgitation. It is useful to assess the four chambers in different views: Apical, basal, and long axis, with the interventricular septum perpendicular to the ultrasound beam in order to visualize better the integrity of the septum. Then, the origin and double crossing of the great arteries must be correctly identified: The left ventricle outflow tract, with the continuity between the interventricular septum and the anterior wall of the ascending aorta; the right ventricle outflow tract, more superior, anterior, almost perpendicular to the axis of the ascending aorta and connecting to the descending aorta in the three-vessel view. Color Doppler is also of help to better visualize the outflow tracts, confirming anterograde flow through the semilunar valves and great arteries, and makes easier the examination of both aortic and ductal archs and their confluence. Pulsed Doppler 
may be used to assess blood flow through the aortic and pulmonic valves in order to confirm normal anterograde flow and detect very high velocities, suggesting valve stenosis. Finally, color and pulsed Doppler are also very useful to identify normal systemic and pulmonary venous return. Figures 1 to 10 illustrate images obtained at early fetal scan by 2D echocardiography and color Doppler in a structurally normal heart. In our experience, the average duration of the complete fetal cardiac scan is over 15 minutes. It essentially depends on the gestational age at the examination, and can be even shorter if there is a favorable fetal lie. In our setting, a subsequent transabdominal echocardiography is scheduled for all our patients at 20 to 22 weeks gestation.

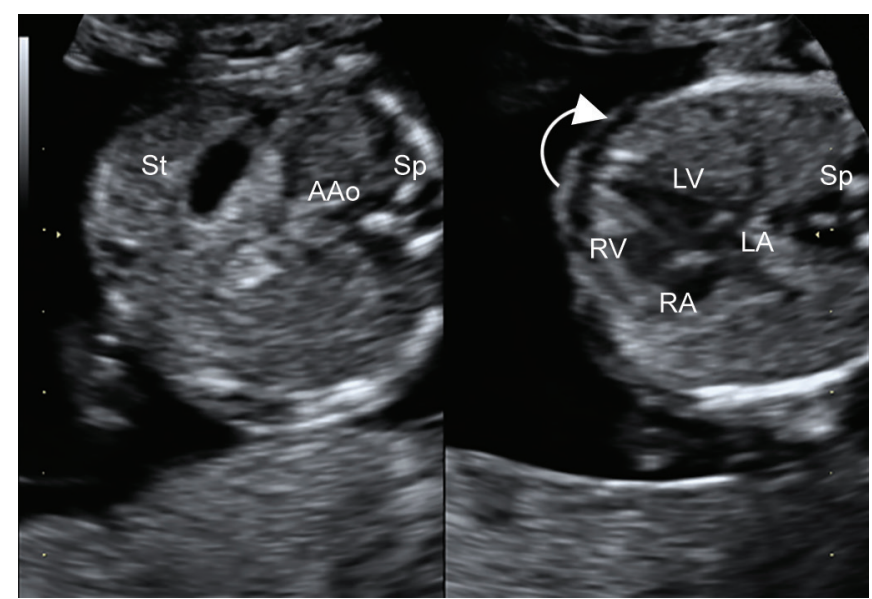

Fig. 1: Early fetal echocardiography by $2 \mathrm{D}$ in a structurally normal heart. Situs visceral. Left: Fetal stomach, cross section of the abdominal aorta, spine and liver. Right: Four-chambers view. Heart axis pointing left, heart occupies one-third of the thorax, majority of heart in left chest

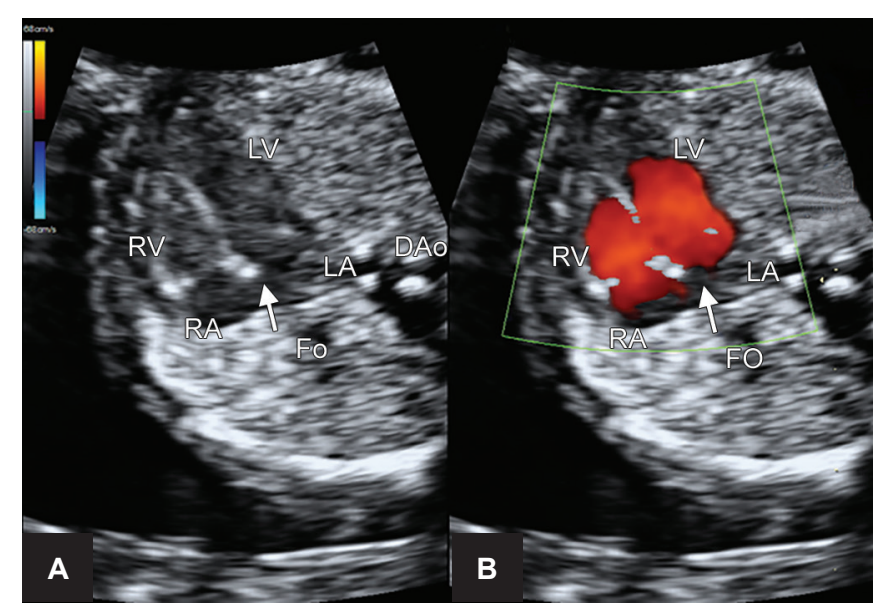

Figs $3 A$ and $B$ : Early fetal echocardiography by $2 \mathrm{D}$ and color Doppler in a structurally normal heart. (A) Four-chamber view-2D. (B) four-chamber view-2D and color Doppler (Abbreviations: RV: Right ventricle; LV: Left ventricle; RA: Right atrium; LA: Left atrium; FO: Foramen ovale; DAo: Descending aorta)
Most of the authors agree that the best window of time to perform the early echocardiography is between 13 and 16 weeks of gestation, since a complete cardiac examination is rarely achieved before the 13th week of gestation. ${ }^{14,17,18,20-22,26}$ Articles on early fetal echocardiography demonstrate an increase in visualization rates of the four-chamber view and the outflow tracts in the last decade, with visualization rates greater than $90 \%$ at 13 weeks gestation. ${ }^{28}$ To maximize the reduction of noninterpretable examinations, early fetal echocardiography should be preferably performed at 13 completed weeks gestation. Using current technology, the four-chamber view and the outflow tracts are often demonstrated by 2D echocardiography only, but color Doppler imaging

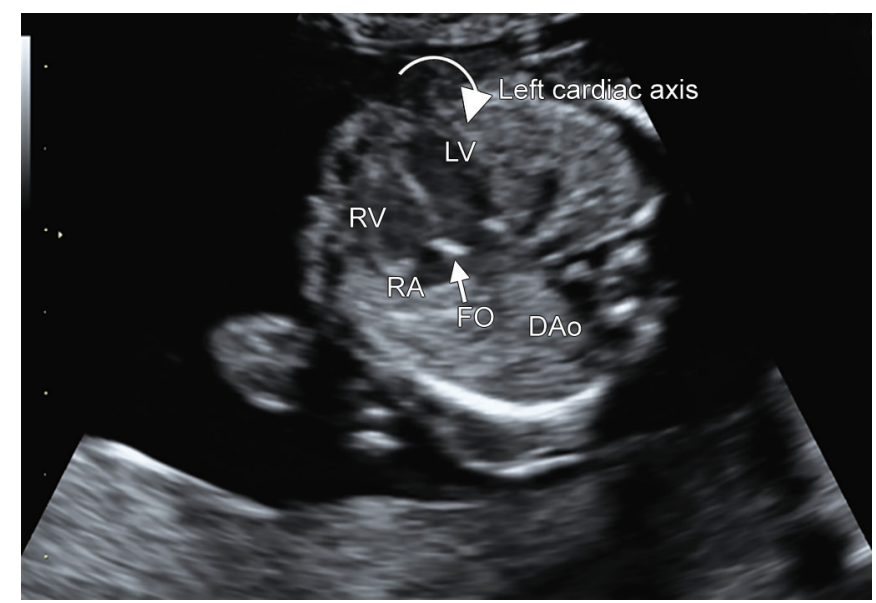

Fig. 2: Early fetal echocardiography by $2 \mathrm{D}$ in a structurally norma heart. The four-chamber view: Normal situs solitus; normal size and axis of the heart in relation to the chest; both atria equal in size, with the foramen ovale flapping within the left atrium; both ventricles equal in size and contractility; atrial and ventricular septa are of normal appearance; tricuspid and mitral valves are normally inserted (Abbreviations: RV: Right ventricle; LV: Left ventricle; RA: Right atrium; LA: Left atrium; FO: Foramen ovale; DAo: Descending aorta)

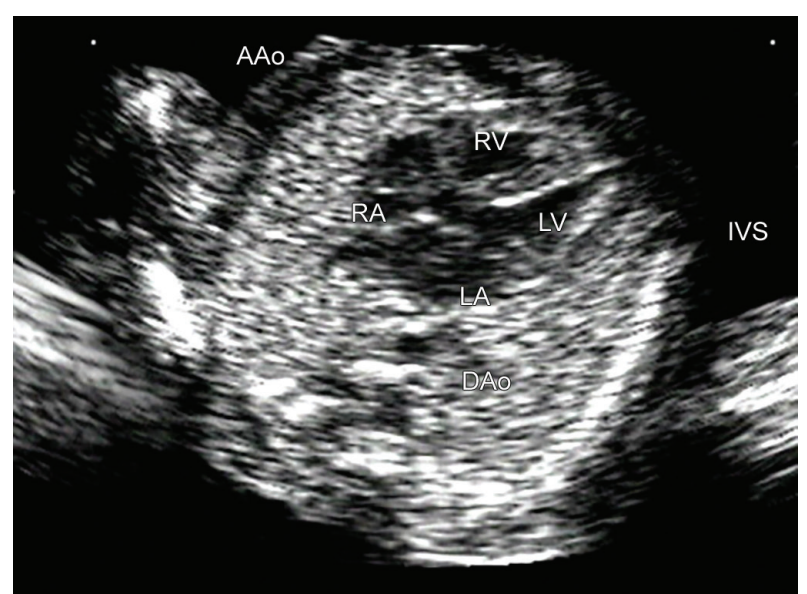

Fig. 4: The five-chamber view: Left ventricle outflow tract in the long axis view showing the continuity between the interventricular septum and the anterior wall of the ascending aorta (Abbreviations: RV: Right ventricle; LV: Left ventricle; RA: Right atrium; LA: Left atrium; AAo: Ascending aorta; DAo: Descending aorta; IVS: Interventricular septum) 

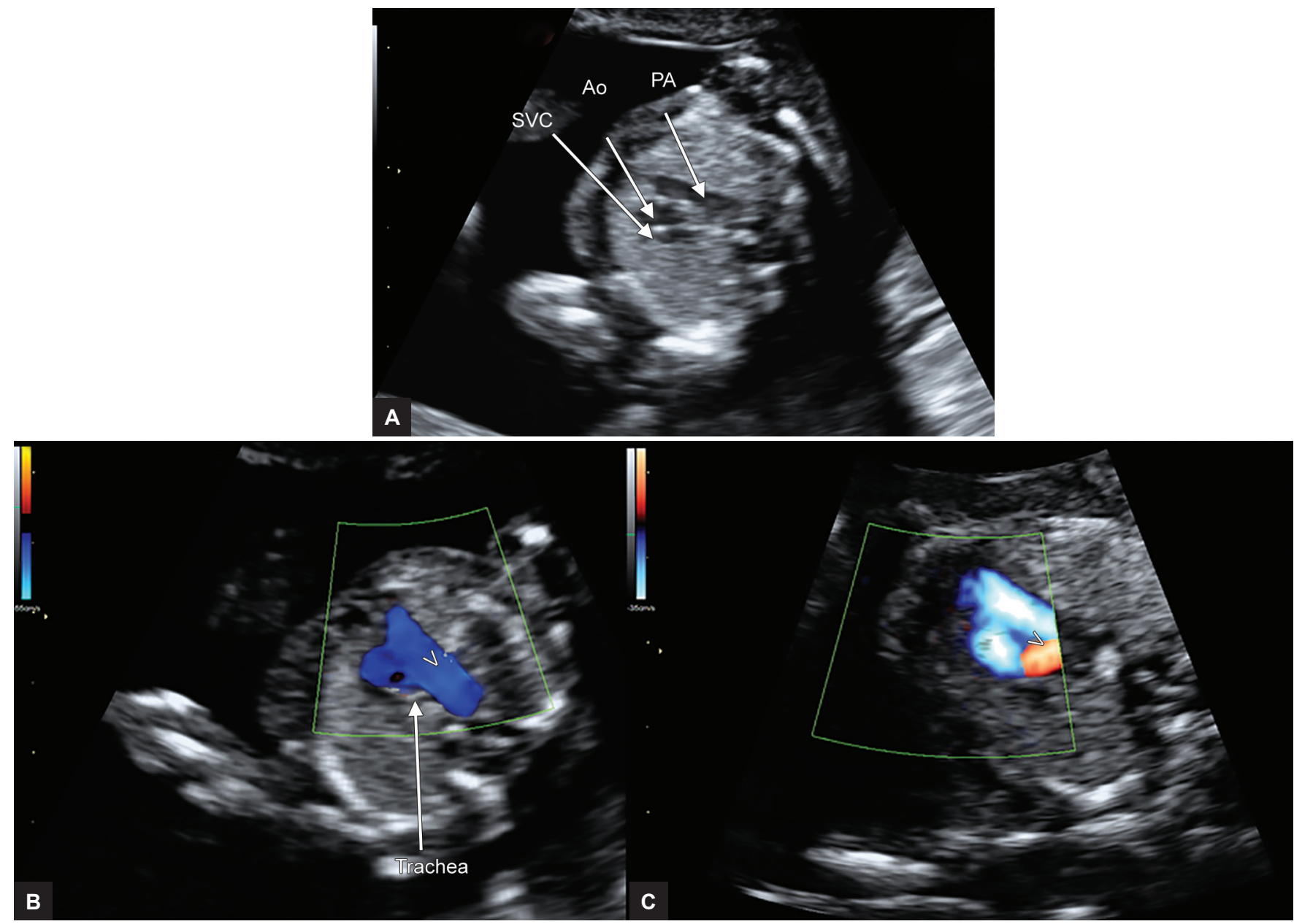

Figs 5A to C: Early fetal echocardiography by 2D, color Doppler and BiFlow in a structurally normal heart. The three-vessel view. Color Doppler is particularly useful to demonstrate the normal $\mathrm{V}$ confluence of the ductal and aortic arch ( $\mathrm{V}$ sign). Note that normally the trachea is located behind the aortic arch. (A) Three-vessels view 2D. (B) threevessels view 2D and color Doppler. (C) three-vessels view 2D and BiFlow (Abbreviations: PA: Pulmonary artery; Ao: Aorta; SVC: Superior vena cava)

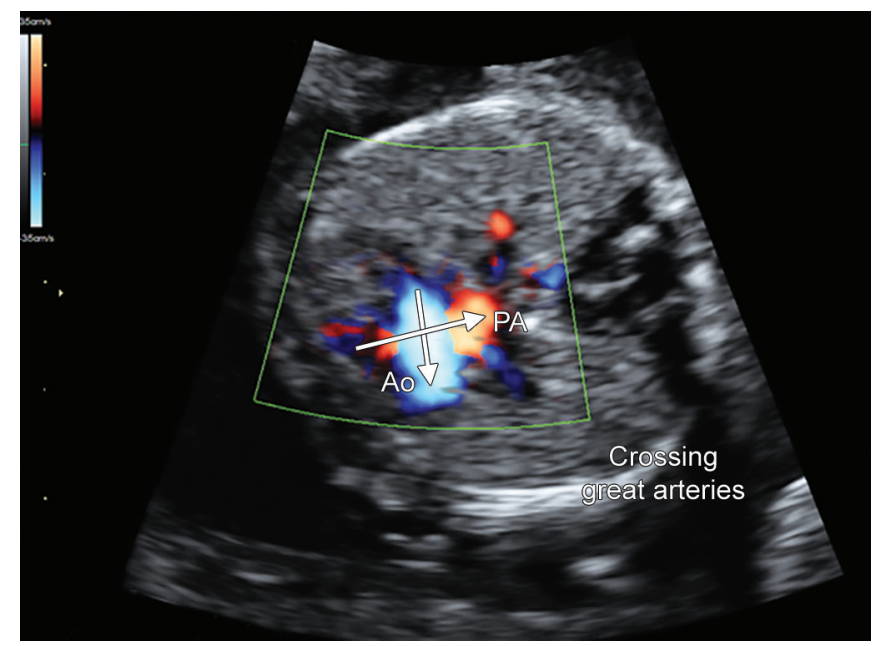

Fig. 6: Early fetal echocardiography by $2 \mathrm{D}$ and BiFlow in a structurally normal heart. BiFlow is particularly useful to demonstrate the crossing of the great arteries (Abbreviations: Ao: Aorta; PA: Pulmonary artery)

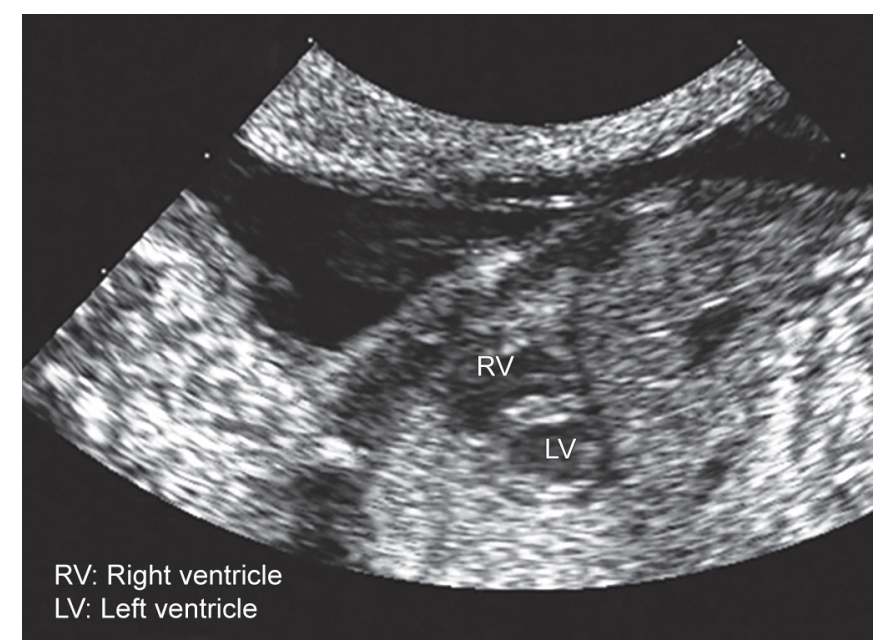

Fig. 7: Early fetal echocardiography by 2D in a structurally normal heart. The short axis view, showing an anterior right ventricle and a posterior left ventricle (Abbreviations: RV: Right ventricle; LV: Left ventricle) 

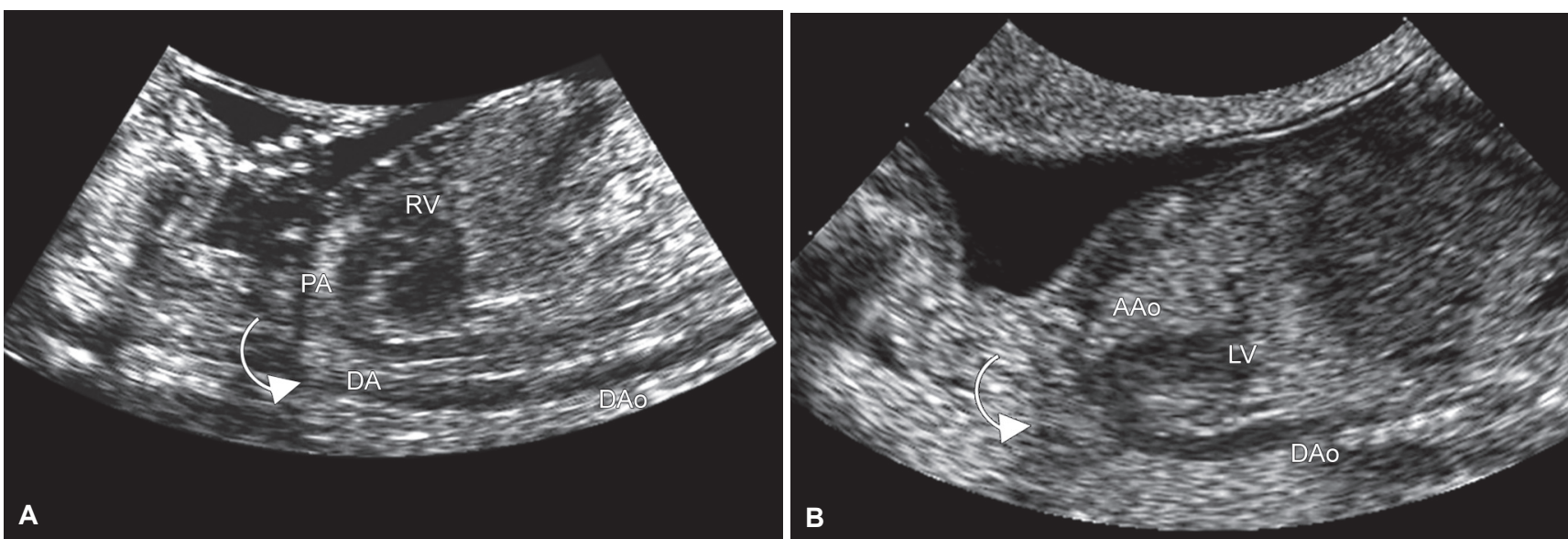

Figs $8 \mathrm{~A}$ and $\mathrm{B}$ : Early fetal echocardiography by $2 \mathrm{D}$ in a structurally normal heart. The left sagittal view of $(A)$ Ductal arch and $(B)$ aortic arch (Abbreviations: RV: Right ventricle; LV: Left ventricle; PA: Pulmonary artery; DA: Ductus arteriosus; DAo: Descending aorta; AAo: Ascending aorta)

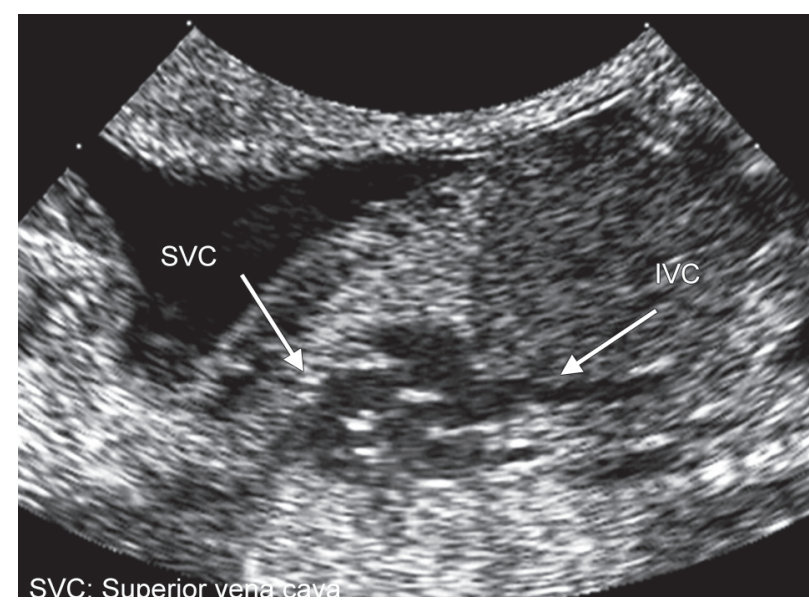

Fig. 9: Early fetal echocardiography by 2D in a structurally normal heart. Systemic venous return to the right atrium throws the superior and inferior vena cava (Abbreviations: SVC: Superior vena cava; IVC: Inferior vena cava)

enhances and makes the identification of the structures faster, increasing the success rate of the examination, and allows even earlier identification of the structures.

\section{DIAGNOSIS OF CONGENITAL HEART DEFECTS}

The first diagnosis of a CHD by early echocardiography was reported by Gembruch et $\mathrm{al}^{32}$. A complete atrioventricular canal defect, with complete heart block and atrioventricular valve regurgitation, was diagnosed at 11 weeks +4 days gestation using a $5-\mathrm{MHz}$ TV probe. The same year, Bronshtein et $\mathrm{al}^{33}$ reported the diagnosis of a ventricular septal defect with overriding aorta and a further case of an isolated ventricular septal defect with pericardial effusion, both cases at 14 weeks gestation. Since then, an increasing number of case reports and series on the early diagnosis of CHD have been reported, both in high-risk and low-risk populations. Tables 1 and 2 summarize some of the largest and most significant studies

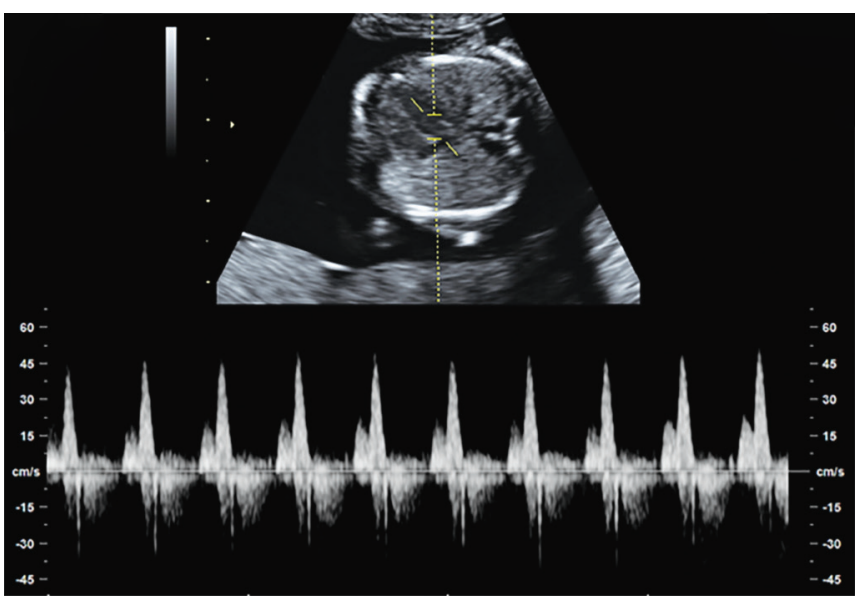

Fig. 10: Early fetal echocardiography by 2D and power Doppler. Normal mitral wave flow by power Doppler

on the detection of CHD using early fetal echocardiography in high-risk and low-risk pregnancies. ${ }^{14,17-22,24-26,34-46}$ Obviously, studies in unselected population report less encouraging results, with lower visualization rates and detection rates. The largest series was published by Bronshtein and Zimmer. ${ }^{20}$ They report the diagnosis of 173 cases of CHD over 36,323 fetuses evaluated by TV ultrasound at 11 to 17 weeks gestation over a 14 -year period of time, with $99 \%$ of scans performed at 14 to 16 weeks gestation and $86 \%$ of them in low-risk population.

Two institutions went further and reported their experience performing the echocardiography as early as between 10 and 13 weeks gestation. ${ }^{22,26}$

The most frequent fetal heart anomalies diagnosed at early echocardiography are summarized in Table 3 (true-positive cases). ${ }^{14,18-21,24-26,34,35,37,39-42,45-46}$ Note that only the main anomaly for each fetus is presented in the table, even though some fetuses had several cardiac 
Table 1: Results of early fetal echocardiography to diagnose cardiac defects in high-risk population (only series with at least 10 cardiac defects diagnosed)

\begin{tabular}{|c|c|c|c|c|c|c|c|c|}
\hline Author, year & Route & $G A$ & Success & Risk & $N$ & Cases & $11-16$ ws & $20-22 w s$ \\
\hline Gembruch, 9314 & TV & $11-16$ & $90.3 \%$ & High & 114 & 13 & $92 \%$ & $100 \%$ \\
\hline Zosmer, $99^{24}$ & TA & $13-17$ & & High & 323 & 27 & $89 \%$ & $96.3 \%$ \\
\hline Simpson, $00^{25}$ & TA & $12-15$ & $98.7 \%$ & High & 229 & 17 & $76 \%$ & $94 \%$ \\
\hline Huggon, $02^{26}$ & TA & $10-14$ & $86.8 \%$ & High & 478 & 68 & $94 \%$ & \\
\hline Haak, $02^{22}$ & TV & $10-13$ & $95.5 \%$ & High & 45 & 13 & $54 \%$ & \\
\hline Bronshtein, $02^{20}$ & TV & $11-17$ & $>99 \%$ & High & 6175 & 46 & $>90 \%$ & \\
\hline Comas, $02^{21}$ & TV & $12-17$ & $94.6 \%$ & High & 337 & 48 & $79 \%$ & $96 \%$ \\
\hline Lopes, $03^{39}$ & TV & $12-16$ & $94,9 \%$ & High & 275 & 37 & $89 \%$ & \\
\hline Weiner, $02^{40}$ & TV & $11-14$ & $97 \%$ & High & 392 & 19 & $58.3 \%$ & \\
\hline Carvalho, $04^{41}$ & TA & $10-16$ & $96 \%$ & High & 230 & 14 & $91.3 \%$ & \\
\hline McAuliffe, $05^{42}$ & TV & $11-16$ & $95 \%$ & High & 160 & 20 & $70 \%$ & \\
\hline Smrcek, $06^{43}$ & TV & $11-14$ & NR & High & 2165 & 35 & $63 \%$ & \\
\hline Weiner, $08^{45}$ & TV & $11-14$ & $94 \%$ & High & 200 & 19 & $68 \%$ & \\
\hline
\end{tabular}

Route: Main approach; TV: Transvaginal; TA: Transabdominal; GA: Range of gestational age at scan, in weeks; Success: Visualization success rate for the complete early fetal echocardiography; N: Total number of pregnancies scanned; Cases: Total number of cardiac defects (pre- and postnatal); 11-16 ws: Percentage of the cardiac defects identified at early echocardiography (weeks); 20-22 ws: Percentage of the cardiac defects identified at mid-trimester echocardiography (weeks); NR: No reported

Table 2: Detection rate of cardiac defects at early ultrasound to screen for congenital malformations in low-risk population

\begin{tabular}{|c|c|c|c|c|c|c|c|}
\hline Author, year & $G A$ & Success & Risk & Normal & Cases & $11-16$ ws & $20-22 w s$ \\
\hline Achiron, $94^{18}$ & $13-15$ & $98 \%$ & Low & 660 & 6 & $50 \%$ & $50 \%$ \\
\hline Hernadi, $97^{34}$ & 12 & & Low & 3991 & 3 & $33 \%$ & $100 \%$ \\
\hline D'Ottavio, $97^{35}$ & $13-15$ & & Low & 3490 & 8 & $25 \%$ & $80 \%$ \\
\hline Yagel, $97^{17}$ & $13-16$ & $99 \%$ & Low & 6924 & 66 & $64 \%$ & $81 \%$ \\
\hline Economides, $98^{36}$ & $12-13$ & & Low & 1632 & 3 & $0 \%$ & $33 \%$ \\
\hline Whitlow, $99^{37}$ & $11-14$ & & Low & 6443 & 10 & $40 \%$ & $60 \%$ \\
\hline Guariglia, $00^{38}$ & $10-16$ & & Low & 3592 & 11 & $18 \%$ & $56 \%$ \\
\hline Rustico, $00^{19}$ & $13-15$ & $<50 \%$ & Low & 4785 & 41 & $10 \%$ & $32 \%$ \\
\hline Bronshtein, $02^{20}$ & $11-17$ & $99 \%$ & Low & 30148 & 127 & $97 \%$ & $99 \%$ \\
\hline Becker, $06^{44}$ & $11-14$ & & Low & 3094 & 86 & $84.2 \%$ & $94 \%$ \\
\hline Volpe, $11^{46}$ & $11-14$ & & Low & 4445 & 42 & $62 \%$ & $93 \%$ \\
\hline
\end{tabular}

GA: Range of gestational age at scan, in weeks; Success: Visualization success rate for the extended cardiac examination (4 chambers + outflow tracts); Normal: Total number of pregnancies screened; Cases: Total number of cardiac defects (pre- and postnatal); 11-16 ws: Percentage of the cardiac defects identified at early scan (weeks); 20-22 ws: Percentage of the cardiac defects identified at mid-trimester scan (weeks)

Table 3: Fetal heart anomalies diagnosed at early echocardiography (true positive cases at early fetal echocardiography)

\begin{tabular}{|c|c|c|c|c|c|c|c|c|c|c|c|c|c|c|c|c|c|c|c|c|}
\hline True + & $A$ & $B$ & $C$ & $D$ & $E$ & $F$ & $G$ & $\mathrm{H}$ & 1 & $J$ & $K$ & $L$ & $M$ & $N$ & 0 & $P$ & $Q$ & $R$ & $S$ & Overall \\
\hline Gembruch, 9314 & & & & 6 & & 1 & 1 & & & & 2 & & 2 & & & & & & & 12 \\
\hline Zosmer, $99^{24}$ & & & 3 & 3 & 2 & 1 & 4 & 2 & 3 & 1 & & & 4 & & & & 1 & & & 24 \\
\hline Rustico, $00^{19}$ & & & & 2 & & 1 & 1 & 1 & & & & & & & & & & & & 5 \\
\hline Simpson, $00^{25}$ & & & 3 & 2 & & & & 3 & 2 & & & & 2 & 1 & & & & & & 13 \\
\hline Huggon, $02^{26}$ & & & 5 & 29 & & 12 & 9 & 1 & & & 1 & & & 1 & 1 & 1 & & & & 60 \\
\hline Bronshtein, $02^{20}$ & 4 & 1 & 4 & 13 & 2 & 9 & 25 & & $31^{*}$ & 22 & 5 & & 18 & & 17 & 3 & 2 & 13 & & 169 \\
\hline Comas, $02^{21}$ & & & 4 & 8 & & 10 & 4 & 1 & 3 & & 2 & 2 & 1 & & & 3 & & & & 38 \\
\hline Achiron, $94^{18}$ & & & & 2 & & & & & 2 & & 1 & & & & 1 & 1 & 1 & & & 8 \\
\hline Hernadi, $97^{34}$ & & & & & & 1 & & & & & & & & & & & & & & 1 \\
\hline D'Ottavio, $97^{35}$ & & & & & & & 2 & & & & & & & & & & 2 & & & 4 \\
\hline Whitlow, $99^{37}$ & & & & & 1 & & 1 & & & & & & & & & 1 & & & & 3 \\
\hline Rustico, $00^{19}$ & & 1 & & & & & 2 & & 1 & & & & & & & & & & & 4 \\
\hline Lopes, $03^{39}$ & & & 2 & 6 & & 11 & 5 & 1 & 1 & 1 & 1 & 3 & 2 & & & & & & & 33 \\
\hline Weiner, $02^{40}$ & & & & 4 & & 1 & 1 & & 2 & 2 & 2 & & & & & & & & 1 & 13 \\
\hline Carvalho $04^{41}$ & & & 1 & 3 & 1 & 1 & 1 & 2 & & 1 & & & & 3 & & 1 & & & & 14 \\
\hline McAuliffe, $04^{42}$ & & & & & 2 & 2 & 2 & & & & & 1 & & 2 & & 2 & 1 & & 2 & 14 \\
\hline Weiner, $08^{45}$ & & & & 4 & & 1 & 2 & & 2 & 1 & 2 & & & & & & & & 1 & 13 \\
\hline Volpe, $11^{46}$ & & & 1 & 7 & & 4 & 7 & 1 & 2 & 1 & & & 2 & & & & & & 1 & 26 \\
\hline Overall & 4 & 2 & 23 & 89 & 8 & 59 & 67 & 12 & 49 & 29 & 16 & 6 & 31 & 7 & 19 & 12 & 7 & 13 & 5 & 374 \\
\hline
\end{tabular}

${ }^{*}$ This series include cases with tetralogy of Fallot and double outlet right ventricle; A: Abnormal veno-atrial connections; B: Atrial septal defects; C: Tricuspid atresia or dysplasia; D: Atrioventricular septal defect; E: Single ventricle; F: Ventricular septal defects; G: Aortic atresia, aortic stenosis, mitral stenosis, hypoplastic left heart; H: Pulmonary atresia or stenosis; I: Tetralogy of Fallot; J: Transposition of great arteries; K: Truncus; L: Double outlet right ventricle; M: Aortic arch anomalies; N: Isomerism; O: Miocardiopathy; P: Ectopia cordis; Q: Complex cardiac defect, others; R: Vascular ring; S: Hypoplastic right heart 
Early Fetal Echocardiography

Table 4: Fetal heart anomalies not detected at early echocardiography (false negative cases at early fetal echocardiography)

\begin{tabular}{|c|c|c|c|c|c|c|c|c|c|c|c|c|c|c|c|}
\hline False - & $A$ & $B$ & $C$ & $D$ & $E$ & $F$ & $G$ & $H$ & $I$ & $J$ & $K$ & $L$ & $M$ & $N$ & Overall \\
\hline Gembruch, $93^{14}$ & & & & & 1 & & & & & & & & & & 1 \\
\hline Hernadi, $97^{34}$ & 1 & & & 1 & & & & & & & & & & & 2 \\
\hline D'Ottavio $97^{35}$ & 1 & & & & 3 & 2 & & & 1 & & & & & & 7 \\
\hline Economides, $98^{36}$ & 1 & & & & & 1 & 1 & & & & & & & & 3 \\
\hline Whitlow, $99^{37}$ & 2 & 1 & & & & 2 & 1 & 1 & & & & & & & 7 \\
\hline Zosmer, $99^{24}$ & & & & & 1 & 1 & & & 1 & & & & & & 3 \\
\hline Rustico, $00^{19}$ & 1 & & & & 4 & 1 & 2 & & 1 & & & & & & 9 \\
\hline Simpson, $00^{25}$ & 3 & & & & & & & & & 1 & & & & & 4 \\
\hline Comas, $02^{21}$ & 4 & 1 & & & 3 & 1 & 1 & & & & & & & & 10 \\
\hline Huggon, $02^{26}$ & 2 & & 2 & & & 1 & & & 2 & & & & & & 7 \\
\hline Bronshtein, $02^{20}$ & & & & & 1 & 1 & & 1 & 1 & & & & & & 4 \\
\hline Lopes, $03^{39}$ & 3 & & & & & & & 1 & & & & & & & 4 \\
\hline Weiner, $02^{40}$ & 3 & & & & 1 & & 1 & & & & & & 1 & & 6 \\
\hline Carvalho $04^{41}$ & 1 & & & & & & & & & & & 1 & & & 2 \\
\hline McAuliffe, $04^{42}$ & 3 & & & & & & & 2 & & 1 & & & & & 6 \\
\hline Becker, $06^{44}$ & & & & & 1 & & 1 & 2 & & & 1 & & 1 & 1 & 6 \\
\hline Weiner, $08^{45}$ & 2 & & & & 1 & & 1 & & 1 & & 1 & & & & 6 \\
\hline Volpe, $11^{46}$ & 7 & 1 & & & 2 & 1 & 1 & 1 & 1 & & & 1 & & & 16 \\
\hline Overall & 34 & 3 & 2 & 1 & 18 & 11 & 8 & 8 & 8 & 1 & 2 & 2 & 2 & 1 & 61 \\
\hline
\end{tabular}

A: Ventricular septal defects; B: Atrial septal defects; C: Abnormal veno-atrial connections; D: Tricuspid atresia or dysplasia; E: Atrioventricular septal defect; F: Aortic atresia, aortic stenosis, hypoplastic left heart; G: Tetralogy of Fallot; H: Transposition of great arteries; I: Aortic arch anomalies; J: Myocardiopathy; K: Absent pulmonary valve, pulmonary stenosis; L: Mitral dysplasia; M: Pulmonary stenosis; N: Total anomalous pulmonary venous drainage

anomalies. It should be noted that defects, such as a small isolated ventricular septal defect or valvular stenosis are not reported in these studies. Table 4 summarizes the published cases of cardiac anomaly not detected in early pregnancy (false-negative cases). ${ }^{14,19-21,24-26,34-37,39-42,45,46}$

The results of these studies support the use of early fetal echocardiography to detect the majority of major CHD in both low-risk and high-risk populations, during the first and early second trimester of pregnancy. The cardiac anomalies detected at this early stage of pregnancy are mainly defects involving the four-chamber view, such as large ventricular septal defects, atrioventricular septal defects, and malformations resulting in asymmetry of the ventricles, indicating that defects solely affecting the outflow tracts are difficult to diagnose in the first trimester of pregnancy. Heart defects diagnosed early in pregnancy tend to be more complex than those detected later, with a higher incidence of associated structural malformations, chromosomal abnormalities, and spontaneous abortions. It is widely accepted that the spectrum of CHD diagnosed during prenatal life is different from that observed in postnatal series, with a higher incidence of associated extracardiac lesions and a significant relationship with chromosomal abnormalities in comparison with postnatal life. ${ }^{3-5,17}$ Furthermore, when the cardiac defects are detected during the early pregnancy, they used to be even more complex, probably corresponding to the most severe spectrum of the disease $\mathrm{e}^{21,25,26}$ and used to cause more severe hemodynamic compromise in the developing fetus. A common finding is the presence of a hygroma or hydrops associated with CHD, whereas this is not so when the diagnosis is done later in pregnancy. ${ }^{1,5,21}$ As a result, many of these fetuses are not going to survive long into the second trimester, but this does not argue against early diagnosis. Indeed, when the intrauterine demise of the fetus occurs days or weeks before the delivery, the pathological examination is certainly more difficult to perform. All these considerations should be taken into account when counseling the parents about complex CHD.

We have previously published our experience in the first multicenter trial in early fetal echocardiography performed in Spain ${ }^{21}$ (Figs 11 to 15). In accordance with other studies, this experience stresses the usefulness of early echocardiography when performed by expert operators on fetus specifically at risk for cardiac defects. Our review of these additional 48 cases contributes to the expanding

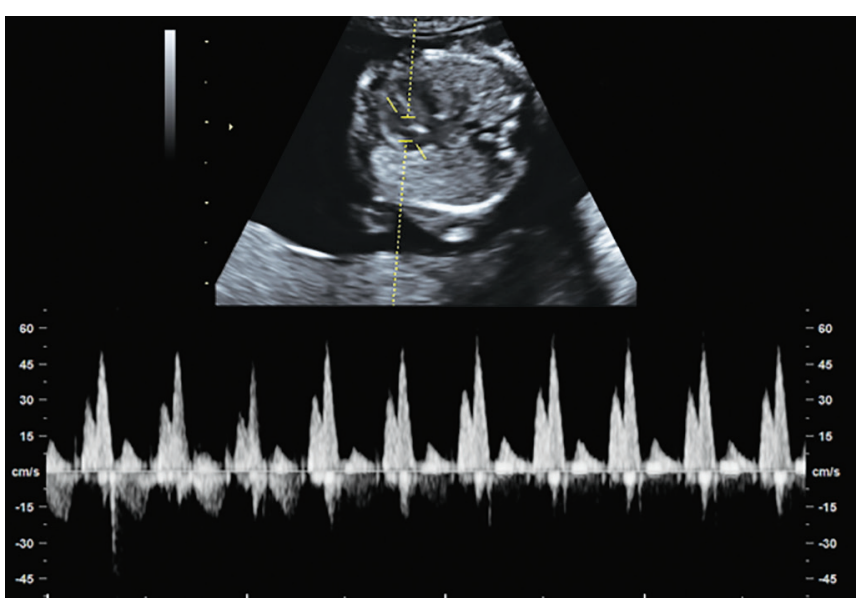

Fig. 11: Early fetal echocardiography by $2 \mathrm{D}$ and power Doppler. Normal tricuspid wave flow by power Doppler 

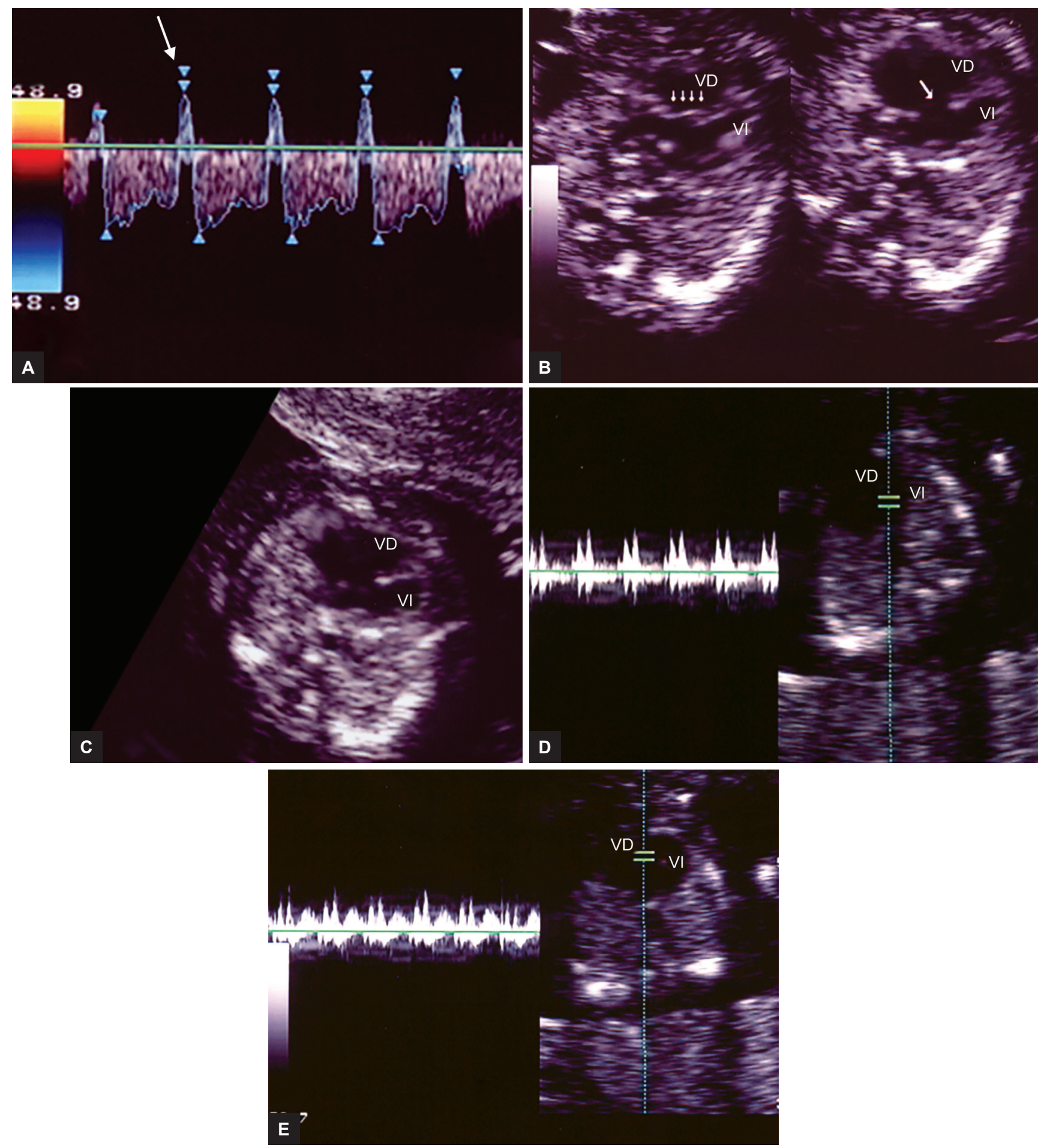

Figs $12 \mathrm{~A}$ to E: Atrioventricular septal defect detected at 13 weeks of gestation in a fetus affected by cystic hygroma and trisomy 21 (A) Note the abnormal reversed A wave in the ductus venosus. (B and C) Note the ventricular septal defect. (D and E) These figures illustrate the mitral and tricuspid diastolic flow, respectively

literature on the ability of TV ultrasonography to detect fetal heart defects in early pregnancy.

\section{ADVANTAGES AND LIMITATIONS}

The first benefit of performing early fetal echocardiography would be an early reassurance of normality in order to relieve anxiety and reduce emotional trauma to the parents at high risk for CHD. Early prenatal diagnosis of CHD will allow us to optimize the genetic counseling to the parents by permitting further testing, such as fetal karyotyping, and in those cases with severe defects it may provide the parents with the option of an earlier and safer termination of pregnancy (TOP). ${ }^{13,14,17}$ In selected cases, there is the possibility of pharmacologic therapy. Furthermore, the correct timing and place for delivery may be planned and arranged well in advance. 

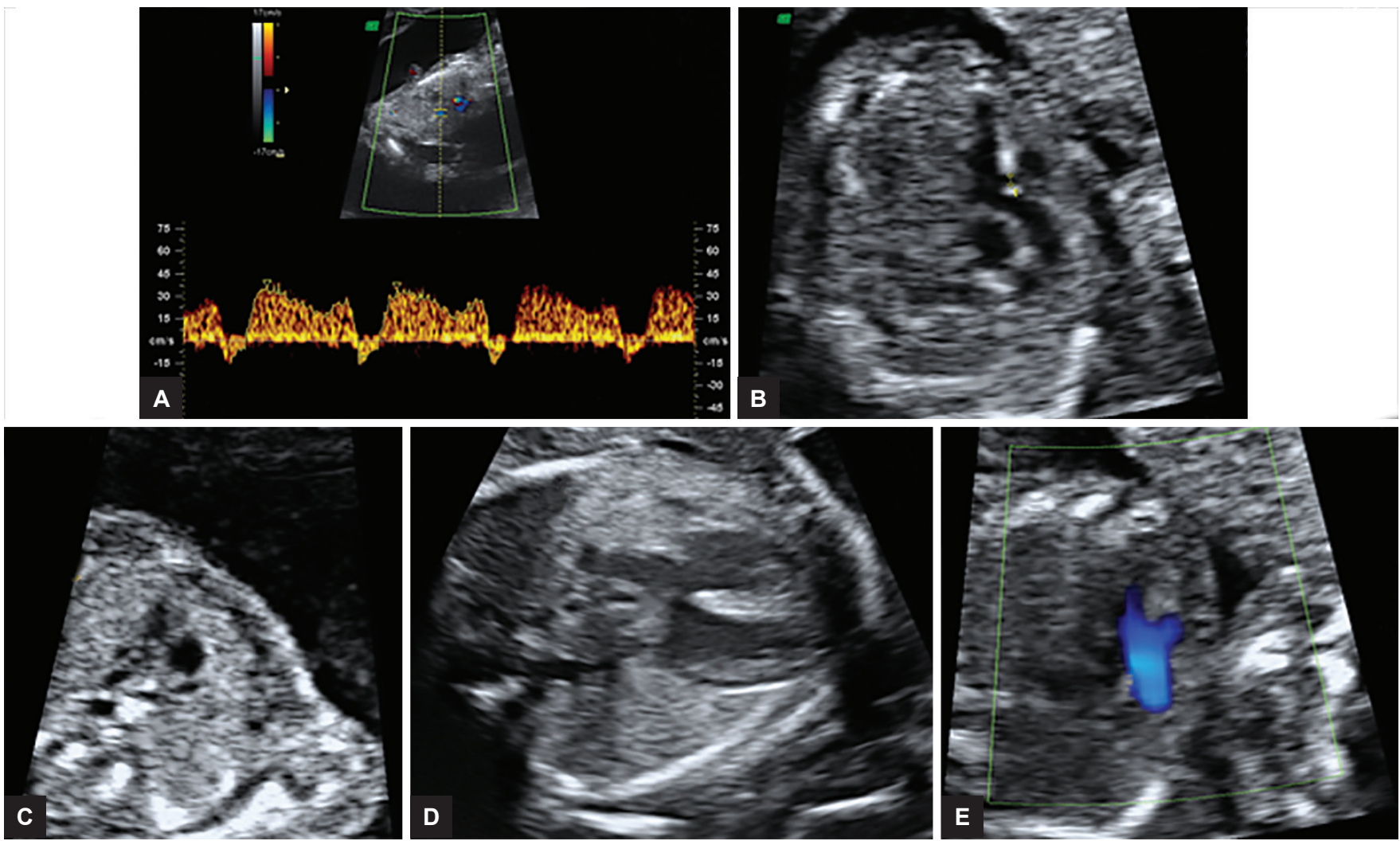

Figs 13A to E: Tetralogy of Fallot detected at 16 weeks of gestation. (A) Note the reverse a wave in ductus venosus flow. (B) note the left ventricular septal defect, $(C)$ the dominance of the aorta compared with the small pulmonary artery at the three-vessel view in the upper mediastinum, (D) cardiac deviation and (E) aortic misalignment
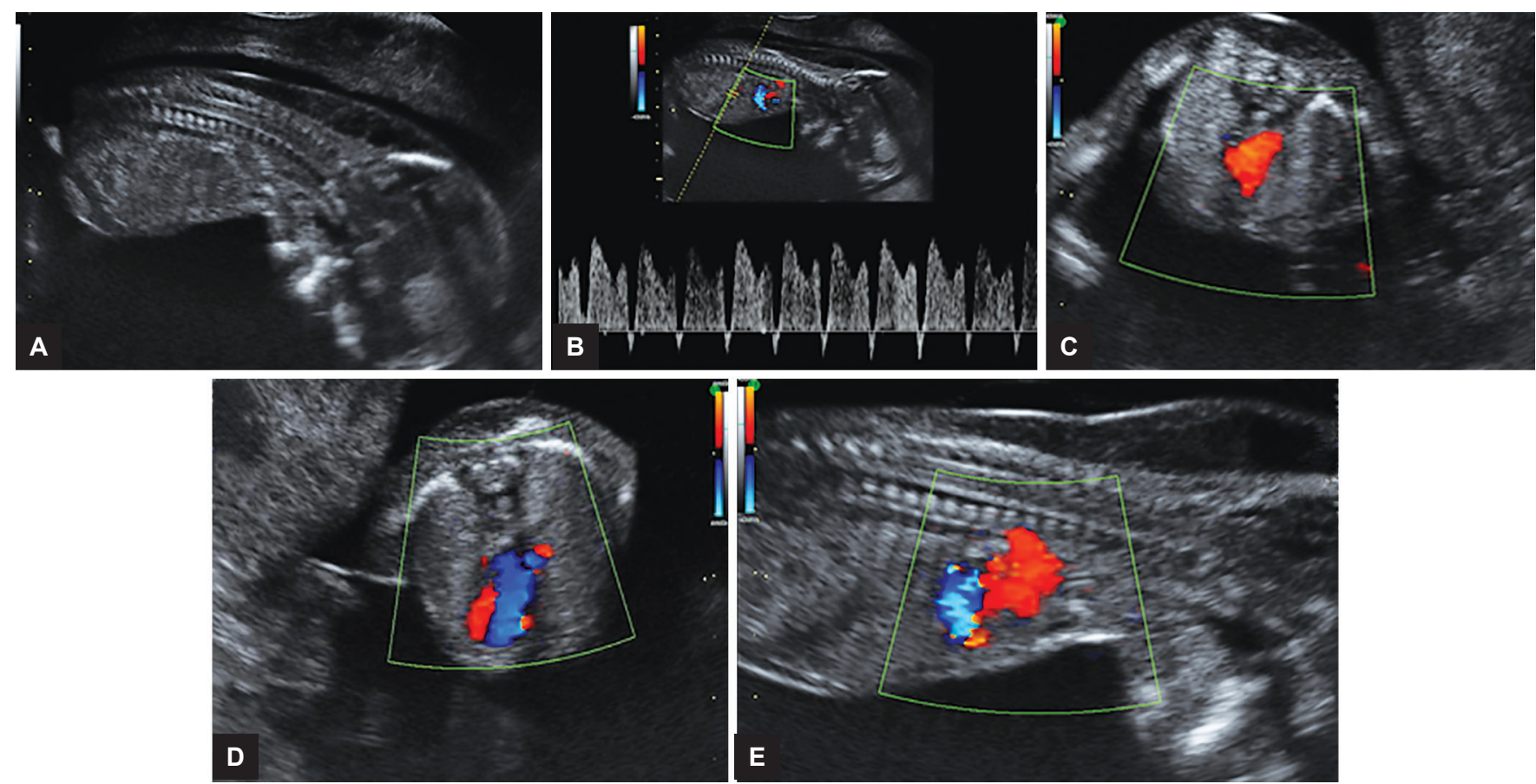

Figs 14A to E: Hypoplastic left heart at 14 weeks of gestation. (A) Note the identification of CHD markers: Increased nuchal translucency; (B) abnormal ductus venosus flow; (C) reverse flow at the three-vessels view; (D) hypoplastic left ventricle with reverse flow with color Doppler, (E) reverse flow in aortic arch

However, there are certain disadvantages of the early scanning, which reduce its diagnostic accuracy compared with the conventional examination at 20 to 22 weeks gestation. ${ }^{1,5,13,14,17}$ The TV technique requires a substantial amount of operator experience, yet it cannot be learned from the second trimester examination as the early transabdominal scan. Unfavorable fetal position or limited angles of insonation due to the less mobile capacity of 

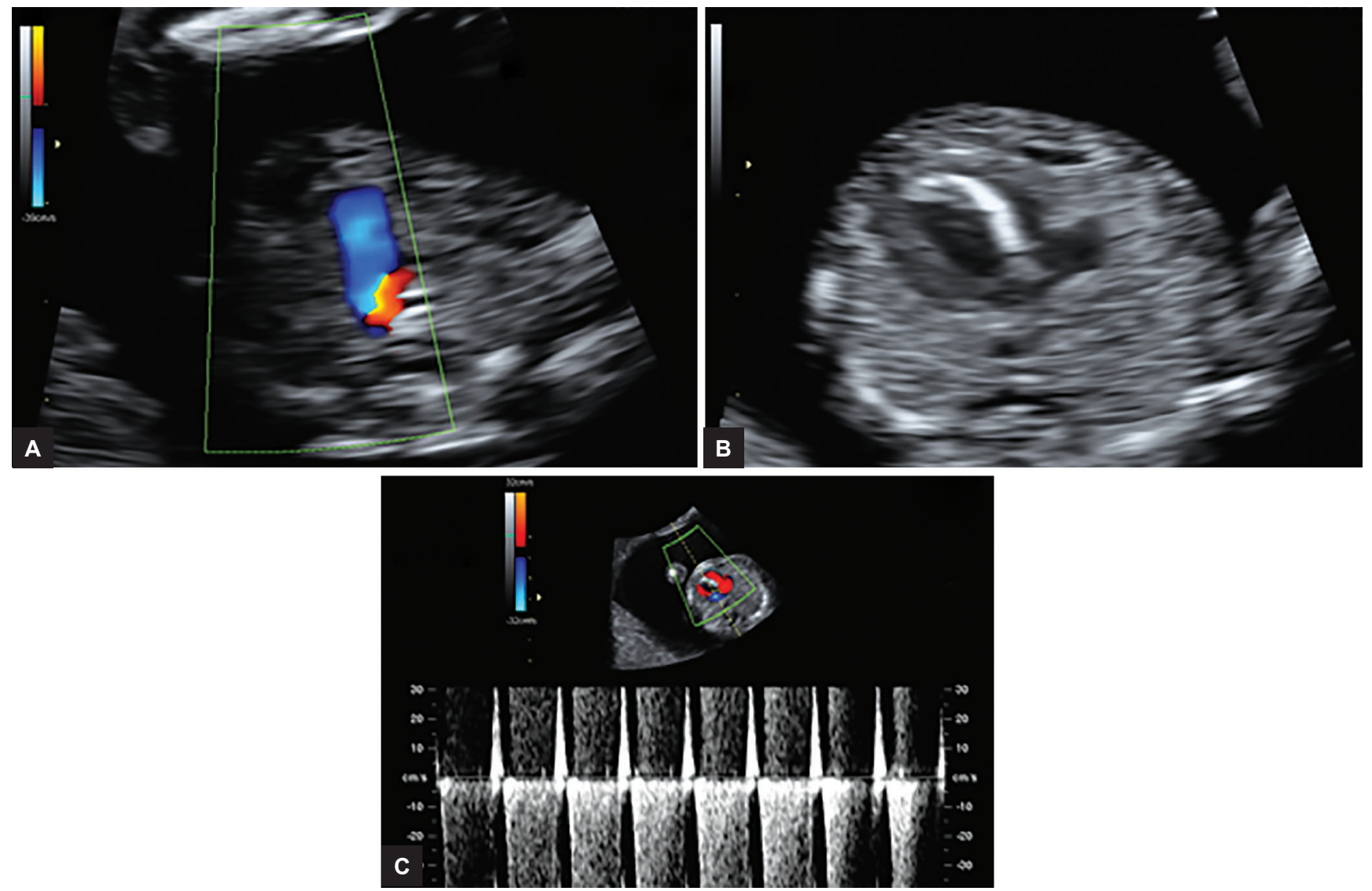

Figs 15A to C: Aortic atresia at 12 weeks of gestation. (A) Note aortic reverse flow in three-vessels view, (B) mitral regurgitation and $(C)$ endocardial fibroelastosis

the TV probe may not be overcome. Also, spatial orientation can be challenging by the TV scan. In such cases, we recommend a transabdominal scan that will help us to quickly asses the situs and obtain a good spatial orientation. The small size of the fetal heart is an important limiting factor to obtain an optimal sonographic visualization, and also to obtain a successful pathological examination, particularly before the 13th week of gestation. At 13 to 14 weeks of gestation, the transverse diameter of the heart at the four-chamber view ranges between 5 and $8 \mathrm{~mm}$, and the great artery diameter at the level of the semilunar valves ranges between 0.8 and $1.8 \mathrm{~mm} .{ }^{5}$ Moreover, this exploration is more time-consuming and requires a high level of training of the examiner. Finally, the biggest disadvantage of first trimester echocardiography is the later manifestation of structural and functional changes in some CHDs. Some cardiac lesions are progressive in nature, such as mild pulmonary and aortic stenosis or coarctation and even hypoplastic left heart syndrome. Some obstructive lesions, as a result of a reduced blood flow, may increase the severity of the lesions, resulting in a restricted growth in chambers or arteries. This may be the biggest disadvantage of performing the early scan. Progression usually is toward a more severe form of lesion that may be sometimes only discernible in the second or even in the third trimester, although, in some rare cases, a regression to a less severe form may be observed. In this sense, the false-negative cases published in literature are particularly instructive demonstrating these limitations. Another disadvantage of early fetal echocardiography is the possible detection of defects that could resolve spontaneously in later pregnancy, such as muscular ventricular septal defects, resulting in unnecessary anxiety in the parents.

Therefore, a normal early examination does not preclude a subsequent abnormal heart development at the second trimester ultrasound, or even in the third trimester or the postnatal period. After a normal early fetal echocardiography, a conventional transabdominal echocardiography at 20 to 22 weeks of gestation is strongly recommended.

\section{PATHOLOGICAL CONFIRMATION}

Pathological confirmation in the case of an early TOP or perinatal death is particularly important in those areas where ultrasound diagnosis is most challenging. Only a complete diagnosis will make an individual genetic counseling possible and will validate the accuracy of early fetal echocardiography as a diagnostic technique. Therefore, we advocate that a precise pathological report has to be compulsory for an adequate assessment of the reliability of early fetal echocardiography. This is still a major drawback in most of the studies. 1,5,21,26 
Termination of pregnancy is an option only before 22 weeks of gestation in our country. Whenever a termination takes place, it is of vital importance to obtain permission for autopsy in order to confirm the diagnosis and search for any other associated malformations. Ideally, this should be performed by a pathologist who is familiar with the small size of the specimen and with special examination techniques, such as dissection microscopy., 5, 22 Current methods of terminating early pregnancies other than using prostaglandins are less recommended because they do not usually allow the retrieval of suitable specimens for appropriate examination to correlate ultrasound and pathological findings. This method allows a more gentle extraction of the embryo or fetus so that a pathological examination for verification of the prenatally diagnosed malformation can be performed. A pathological investigation after TOP following the diagnosis of a CHD should be always recommended, preferably in referral laboratories, being of paramount importance to validate early echocardiography. In particular, semilunar valve and aortic arch defects are usually underdiagnosed. We are aware of some cases in which Doppler findings, such as turbulent flow and very high velocities, are more reliable to diagnose valve stenosis than pathological examination, even during the second trimester. Indeed, this is a problem and a major challenge not only for ultrasonographers but also for pathologists.

\section{INDICATIONS OF EARLY FETAL ECHOCARDIOGRAPHY}

Since most CHDs are detected in low-risk pregnancies, and knowing the high prevalence of heart defects in a nonselected population (incidence of CHD in low risk population $1 / 238^{20}$ ), some authors suggest that an early detailed cardiac examination should be performed in all pregnant women. ${ }^{17,20}$ Indeed, very few cardiac defects have been identified in pregnancies in which a family history was the main indication for early fetal echocardiography, which is consistent with the recurrence rate of 2 to $3 \%$ for siblings. The main value of the early scan in such family-risk cases lies in the reassurance that it gives to the parents. As we have previously stated, in most of the studies, early echocardiography is somewhat less reliable and may result in higher false-negative and falsepositive results in comparison with the 20 to 22 weeks transabdominal echocardiography. Besides, early echocardiography is most time-consuming and requires a high level of expertise of the examiner. Therefore, it is difficult to offer this scan as a screening test to the general population. In this context, the identification of a high-risk collective is of paramount importance.

Currently, the importance of the aforementioned limitations of early fetal cardiac examination justifies restriction of its use to fetuses at high risk of having cardiac anomalies. $5,10,14,18,21,22,26,47$ The indications proposed for early fetal echocardiography are:

- Increased NT ( $>95$ th or 99th centile) is the main indication of referral in all recently reported studies;

- Abnormal DV blood flow and/or tricuspid regurgitation (TR), regardless of the measurement of the NT;

- Fetuses affected by other structural malformations: Hygroma, hydrops, omphalocele, situs inversus, arrhythmia;

- Monochorionic placentation in multiple gestation;

- Suspected cardiac anomalies at screening ultrasound;

- Pregestational diabetes of the mother;

- High-risk family, with a previously affected child, a first-degree relative affected by a CHD, or a genetic disease in which CHDs are common;

- Women at high risk of chromosomal abnormality declining invasive test for karyotyping; and

- Pregnancies affected by a chromosomal abnormality. Currently, as long as the sensitivity, specificity, and predictive value of early echocardiography are still unclear, this examination should be generally reserved for patients at high risk for CHD. However, only the accumulation of results from carefully collaborative studies as the present series will clearly define the role of early TV echocardiography.

\section{RESEARCH DIRECTIONS}

Accumulating evidence supports the role of 2D fetal echocardiography for the diagnosis of major CHDs in the first trimester of pregnancy. ${ }^{48-52}$ The published pooled sensitivity from the more recent studies is $78.6 \%$ with a specificity of $98.9 \%$ (positive predictive value $72.3 \%$ and negative predictive value $91.2 \%) .{ }^{49}$ Nowadays, there is no doubt that early fetal echocardiography is feasible and highly sensitive and specific in experienced hands.

The early sonographic markers that have been investigated in their relation to CHDs are increased NT, abnormal flow in the DV, and TR. Two current approaches have been proposed for the use of the algorithm combining NT, DV Doppler, and TR to estimate the patient-specific risk for major CHD. The first one is to define the risk cut-off that selects the patients requiring referral for specialist fetal echocardiography. The risk increases exponentially with NT thickness from 1 per 1,000 in those with NT at or below the 95th centile to 7 per 1,000 for NT between the 95th and 99th centile and 58 per 1,000 for NT above the 99th centile. The risk is further increased if there is DV reversed a-wave, TR, or both and is decreased if flow in the DV and across the tricuspid valve is normal. The second approach is to define as high risk all cases with TR, DV reversed a-wave, or both, which constitute $3 \%$ of the population and contain $48 \%$ of those with major cardiac defects. If cases with NT 
above the 99th centile are also included, the screen-positive rate would increase to $4 \%$ and the estimated detection rate would be $52 \%$. If there are available resources for performing fetal echocardiography in $8 \%$ of the population, then the NT cut-off for defining the high-risk group could be reduced to the 95th percentile, with an increase in the estimated detection rate to $58 \%{ }^{53}$

The value of first- and second trimester maternal serum biochemical markers in screening for fetal CHDs is a recent research hypothesis under investigation. A case-control study of 68 cases of isolated fetal CHDs and 340 normal controls at 11 to 13 weeks of gestation reported lower maternal serum placental growth factor (PLGF) levels in CHD (0.80 vs 1.00 multiple of median). ${ }^{54}$ This decrease in PLGF was observed in conotruncal and valve defects, but not in left heart defects. Interestingly, the decrease in serum PLGF was not related to impaired placental perfusion. Moreover, recent data suggest that an imbalance of angiogenic-antiangiogenic factors is associated with developmental defects of the human hearts. ${ }^{55,56}$ A case-control study of 306 cases of fetal CHDs and 1224 no CHD controls reported abnormal second trimester serum a-fetoprotein, human chorionic gonadotrophin, and unconjugated estriol in the CHD group. ${ }^{57}$ Nevertheless, nowadays, the value of first- and second trimester maternal serum biochemical markers in screening for fetal CHDs remains to be determined.

The use of four-dimensional (4D) spatiotemporal image correlation (STIC) has been also proposed as helpful in supplying earlier detailed information. ${ }^{49}$ Recent studies support the role of 4D sonography in the identification of CHD between 11 and 15 weeks of pregnancy. ${ }^{58,59}$ Interestingly, Espinoza et $\mathrm{al}^{59}$ have demonstrated that 4D fetal echocardiography can be performed between 11 and 15 weeks gestation, and that 4D volume data sets obtained from fetuses in the first and early second trimesters can be remotely acquired and accurately interpreted by different centers. Standardized planes for fetal echocardiography can be obtained from 4D volume data sets obtained in the first trimester of pregnancy in a reproducible manner. ${ }^{60}$ According to Bennasar et al, ${ }^{61}$ 4D fetal echocardiography in the first trimester can identify CHD with 95.3\% accuracy. Although 2D ultrasound remains superior to $4 \mathrm{D}-\mathrm{STIC}$ at 11 to 14 weeks, this new technology can bring us an additional tool to improve the current efficiency for early detection of CHD. Going further, the fetal intelligent navigation echocardiography (FINE) method, used transabdominally to visualize nine standard planes to STIC volumes during the second half of the pregnancy, could potentially be another exciting tool for the near future, although it is still not tested in early fetal echocardiography. ${ }^{62}$

Recently, the introduction of a key combination of the more sensitive obstetric and cardiologic variables has been suggested to facilitate the formulation of a possible flowchart as a guide for $\mathrm{CHD}$ at-risk pregnancies. ${ }^{52}$ According to this recent experience, the strategic combination of already acquired or new diagnostic and biotechnological tools (such as "aneuploidy sonographic markers," early fetal echocardiography, or genetic analysis) could be analyzed based on their specific statistic reliability and used as key criteria for a clinical score to be included in the management of CHD "at-risk" pregnancies.

\section{RESEARCH DIRECTIONS}

- The development of algorithms for the screening for CHD in the first trimester, using a combination of maternal and pregnancy characteristics, NT, DV Doppler, and TR.

- The value of first- and second trimester maternal serum biochemical markers in screening for fetal CHDs.

- Prospective assessment of the routine implementation of tools, such as TV ultrasound, STIC technology, or FINE algorithm for improving the detection rate of $\mathrm{CHD}$.

- The introduction of a key combination of the more sensitive obstetric and cardiologic variables, including the use of new technologies, should facilitate the formulation of a possible flowchart as a guide for CHD at-risk pregnancies. Studies are currently underway to develop a flowchart by introducing a more complete clinical score, which could also include new CHD-sensitive molecular markers (microribonucleic acids) detectable in maternal peripheral blood.

\section{PRACTICE POINTS}

- First trimester detection of CHD is feasible, but early detailed assessment of the fetal heart requires a high level of expertise in early anomaly scanning and fetal echocardiography.

- The detection rate varies according to the type of the cardiac abnormality.

- The detection of major CHDs at 11 to 13 weeks could be improved if we use easily detectable markers for screening for CHD, as NT, DV, or TR.

- The detection rate could be improved if the ultrasound assessment at the first trimester follows structured protocols.

- The detection rate of CHD could be improved by the use of TV ultrasound and newer techniques.

- The limitations of fetal echocardiography in the first trimester must be borne in mind, and resorting to follow-up midgestational echocardiography should always be considered. 


\section{CONCLUSION (I)}

Fetal echocardiography performed by expert operators is reliable for an early reassurance of normal cardiac anatomy.

- Transvaginal sonography enables good visualization of fetal heart earlier in gestation. The fourchamber view and the extended examination to the great vessels can be imaged in almost $100 \%$ at 13 to 14 weeks of gestation. Less than $5 \%$ of patients will need a repeated scan because of inadequate visualization.

- The combination of TV and transabdominal routes and the application of color Doppler enhance visualization.

- Most CHD are detected in low-risk population. As we cannot perform a targeted fetal echocardiography as a screening test, we need to improve the identification of high-risk group pregnancies. Increased NT at 10 to 14 weeks scan and, maybe, DV blood flow assessment seem to be the newest and most promising risk factors for fetal $\mathrm{CHD}$, and may be particularly useful during the first trimester.

- Currently, early fetal echocardiography should be offered to high-risk pregnancies. Some authors advocate routine early extended cardiac examination in low-risk pregnancies. At present, as long as the sensitivity, specificity, and predictive values of early echocardiography are still unclear, this examination should be generally reserved for patients at high risk for CHD.

- Whenever a normal heart is diagnosed in the early scan, it has to be supplemented with the conventional transabdominal examination at 20 to 22 weeks gestation.

\section{CONCLUSION (II)}

Fetal echocardiography performed by expert operators is reliable to diagnose most major structural heart defects in the first and early second trimester of pregnancy.

- Cardiac defects diagnosed early in pregnancy tend to be more complex than those detected later on and used to cause more severe hemodynamic compromises in the developing fetus.

- Many CHDs can be detected at the beginning of the second trimester.

- The incidence of associated structural malformations, chromosomal abnormalities, and spontaneous abortions is significantly high.

- A complete workup including pathological and karyotype evaluation should be warranted in order to provide parents with a proper genetic counseling, which is extremely difficult to obtain if spontaneous loss of the pregnancy occurs.

- The small size of specimens at this time of gestation renders pathological examination difficult and requires high expertise and careful inspection, irrespective of the technique used for termination.

- Clinical follow-up in the neonate and postmortem examination if TOP is undertaken are essential to assess the actual role of early fetal echocardiography.

\section{REFERENCES}

1. Campbell S, Allan L, Benacerraf B, Copel JA, Carvalho JS, Chaoui R. Isolated major congenital heart disease (Opinion.). Ultrasound Obstet Gynecol 2001 May;17:370-379.

2. Mitchell SC, Korones SB, Berendes HW. Congenital heart disease in 56,109 births. Incidence and natural history. Circulation 1971 Mar;43(3):323-332.

3. Allan LD, Sharland GK, Milburn A, Lockhart SM, Groves AM, Anderson RH, Cook AC, Fagg NL. Prospective diagnosis of 1,006 consecutive cases of congenital heart disease in the fetus. J Am Coll Cardiol 1994 May;23(6):1452-1458.

4. Allan LD. Fetal cardiology. Curr Opin Obstet Gynecol 1996 Apr;8(2):142-147.

5. Gembruch U. Prenatal diagnosis of congenital heart disease. Prenat Diagn 1997 Dec;17(13):1283-1298.

6. Todros T. Prenatal diagnosis and management of fetal cardiovascular malformations. Curr Opin Obstet Gynecol 2000 Apr;12(2):105-109.

7. LeviS, Schaaps JP, De Havay P, Coulon R, Defoort P. End-result of routine ultrasound screening for congenital anomalies: the Belgian Multicentric study 1984-92. Ultrasound Obstet Gynecol 1995 Jun;5(6):366-371.

8. Hyett J, Perdu M, Sharland G, Snijders R, Nicolaides KH. Using fetal nuchal translucency to screen for major congenital cardiac defects at 10-14 weeks of gestation: population based cohort study. BMJ 1999 Jan;318(7176):81-85.

9. Devine PC, Simpson LL. Nuchal translucency and its relationship to congenital heart disease. Semin Perinatol 2000 Oct;24(5):343-351.

10. Matias A, Huggon I, Areias JC, Montenegro N, Nicolaides KH. Cardiac defects in chromosomally normal fetuses with abnormal ductus venosus blood flow at 10-14 weeks. Ultrasound Obstet Gynecol 1999 Nov;14(5):307-310.

11. Bilardo CM, Müller MA, Zikulnig L, Schipper M, Hecher K. Ductus venosus studies in fetuses at high risk for chromosomal or heart abnormalities: relationship with nuchal translucency measurement and fetal outcome. Ultrasound Obstet Gynecol 2001 Apr;17(4):288-294.

12. Johnson P, Sharland G, Maxwell D, Allan L. The role of transvaginal sonography in the early detection of congenital heart disease. Ultrasound Obstet Gynecol 1992 Jul;2(4):248-251.

13. Bronshtein M, Zimmer EZ, Gerlis LM, Lorber A, Drugan A. Early ultrasound diagnosis of fetal congenital heart defects in high-risk and low-risk pregnancies. Obstet Gynecol 1993 Aug;82(2):225-229.

14. Gembruch U, Knöpfle G, Bald R, Hansmann M. Early diagnosis of fetal congenital heart disease by transvaginal echocardiography. Ultrasound Obstet Gynecol 1993 Sep;3(5):310-317. 
15. Achiron R, Tadmor O. Screening for fetal anomalies during the first trimester of pregnancy: transvaginal versus transabdominal sonography. Ultrasound Obstet Gynecol 1991 May;1(3):186-191.

16. D'Amelio R, Giorlandino C, Masala L, Garofalo M, Martinelli M, Anelli G, Zichella L. Fetal echocardiography using transvaginal and transabdominal probes during the first period of pregnancy: a comparative study. Prenat Diagn 1991 Feb;11(2): 69-75.

17. Yagel S, Weissman A, Rotstein Z, Manor M, Hegesh J, Anteby E, Lipitz S, Achiron R. Congenital heart defects: natural course and in utero development. Circulation 1997 Jul;96(2):550-555.

18. Achiron R, Rotstein Z, Lipitz S, Mashiach S, Hegesh J. First trimester diagnosis of fetal congenital heart disease by transvaginal ultrasonography. Obstet Gynecol 1994 Jul;84(1):69-72.

19. Rustico MA, Benettoni A, D'Ottavio G, Fischer-Tamaro L, Conoscenti GC, Meir Y, Natale R, Bussani R, Mandruzzato GP. Early screening for fetal cardiac anomalies by transvaginal echocardiography in an unselected population: the role of operator experience. Ultrasound Obstet Gynecol 2000 Dec;16(7):614-619.

20. Bronshtein M, Zimmer EZ. The sonographic approach to the detection of fetal cardiac anomalies in early pregnancy. Ultrasound Obstet Gynecol 2002 Apr;19(4):360-365.

21. Comas Gabriel C, Galindo A, Martínez JM, Carrera JM, Gutiérrez-Larraya F, De la Fuente P, Puerto B, Borrell A. Early prenatal diagnosis of major cardiac anomalies in a high-risk population. Prenat Diagn 2002 Jul;22(7):586-593.

22. Haak MC, Twisk JW, Van Vugt JM. How successful is fetal echocardiographic examination in the first trimester of pregnancy? Ultrasound Obstet Gynecol 2002 Jul;20(1):9-13.

23. Carvalho JS, Moscoso G, Ville Y. First trimester transabdominal fetal echocardiography. Lancet 1998 Apr;351(9108):1023-1027.

24. Zosmer N, Souter VL, Chan CS, Huggon IC, Nicolaides KH. Early diagnosis of major cardiac defects in chromosomally normal fetuses with increased nuchal translucency. Br J Obstet Gynaecol 1999 Aug;106(8):829-833.

25. Simpson JM, Jones A, Callaghan N, Sharland GK. Accuracy and limitations of transabdominal fetal echocardiography at 12-15 weeks of gestation in a population at high risk for congenital heart disease. BJOG 2000 Dec;107(12):1492-1497.

26. Huggon IC, Ghi T, Cook AC, Zosmer N, Allan LD, Nicolaides KH. Fetal cardiac abnormalities identified prior to 14 weeks' gestation. Ultrasound Obstet Gynecol 2002 Jul;20(1):22-29.

27. DeVore GR. First-trimester fetal echocardiography: is the future now? Ultrasound Obstet Gynecol 2002 Jul;20(1):6-8.

28. Haak MC, van Vugt JM. Echocardiography in early pregnancy: review of literature. J Ultrasound Med 2003 Mar;22(3):271-280.

29. DeVore GR. Color Doppler examination of the outflow tracts of the fetal heart: a technique for identification of cardiovascular malformations. Ultrasound Obstet Gynecol 1994 Nov;4(6):463-471.

30. Wladimiroff JW, Seelen JC. Doppler tachometry in early pregnancy. Development of fetal vagal function. Eur J Obstet Gynecol Reprod Biol 1972;2:55-63.

31. Schats R, Jansen CA, Wladimiroff JW. Embryonic heart activity: appearance and development in early human pregnancy. Br J Obstet Gynaecol 1990 Nov;97(1):989-994.

32. Gembruch U, Knöpfle G, Chatterjee M, Bald R, Hansmann M. First-trimester diagnosis of fetal congenital heart disease by transvaginal two-dimensional and Doppler echocardiography. Obstet Gynecol 1990 Mar;75(3 Pt 2):496-498.
33. Bronshtein M, Siegler E, Yoffe N, Zimmer EZ. Prenatal diagnosis of ventricular septal defect and overriding aorta at 14 weeks' gestation, using transvaginal sonography. Prenat Diagn 1990 Nov;10(11):697-702.

34. Hernádi L, Töröcsik M. Screening for fetal anomalies in the 12th week of pregnancy by transvaginal sonography in an unselected population. Prenat Diagn 1997 Aug;17(8):753-759.

35. D'Ottavio G, Meir YJ, Rustico MA, Pecile V, Fischer-Tamaro L, Conoscenti G, Natale R, Mandruzzato GP. Screening for fetal anomalies by ultrasound at 14 and 21 weeks. Ultrasound Obstet Gynecol 1997 Dec;10(6):375-380.

36. Economides DL, Braithwaite JM. First trimester ultrasonographic diagnosis of fetal structural abnormalities in a low risk population. Br J Obstet Gynaecol 1998 Jan;105(1):53-57.

37. Whitlow BJ, Chatzipapas IK, Lazanakis ML, Kadir RA, Economides DL. The value of sonography in early pregnancy for the detection of fetal abnormalities in an unselected population. Br J Obstet Gynaecol 1999 Sep;106(9):929-936.

38. Guariglia L, Rosati P. Transvaginal sonographic detection of embryonic-fetal abnormalities in early pregnancy. Obstet Gynecol 2000 Sep;96(3):328-332.

39. Lopes LM, Brizot ML, Lopes MA, Ayello VD, Schultz R, Zugaib M. Structural and functional cardiac abnormalities identified prior to 16 weeks' gestation in fetuses with increased nuchal translucency. Ultrasound Obstet Gynecol 2003 Nov;22(5):470-478.

40. Weiner Z, Lorber A, Shalev E. Diagnosis of congenital cardiac defects between 11 and 14 weeks' gestation in high-risk patients. J Ultrasound Med 2002 Jan;21(1):23-29.

41. Carvalho JS, Moscoso G, Tekay A, CampbellS, Thilaganathan B, Shinebourne EA. Clinical impact of first and early second trimester fetal echocardiography on high risk pregnancies. Heart 2004 Aug;90(8):921-926.

42. McAuliffe FM, Trines J, Nield LE, Chitayat d, Jaeggi E, Hornberger LK. Early fetal echocardiography - a reliable prenatal diagnosis tool. Am J Obstet Gynecol 2005 Sep;193(3 Pt 2):1253-1259.

43. Smrcek JM, Berg C, Geipel A, Fimmers R, Axt-Fliedner R, Diedrich K, Gembruch U. Detection rate of early fetal echocardiography and in utero development of congenital heart defects. J Ultrasound Med 2006 Feb;25(2):187-196.

44. Becker R, Wegner RD. Detailed screening for fetal anomalies and cardiac defects at the 11-13 week scan. Ultrasound Obstet Gynecol 2006 Jun;27(6):613-618.

45. Weiner Z, Weizman B, Beloosesky R, Goldstein I, Bombard A. Fetal cardiac scanning performed immediately following an abnormal nuchal translucency examination. Prenat Diagn 2008 Oct;28(10):934-938.

46. Volpe P, Ubaldo P, Volpe N, Campobasso G, De Robertis V, Tempesta A, Volpe G, Rembouskos G. Fetal cardiac evaluation at 11-14 weeks by experienced obstetricians in a low-risk population. Prenat Diagn 2011 Nov;31(11):1054-1061.

47. Johnson B, Simpson LL. Screening for congenital heart disease: a move toward earlier echocardiography. Am J Perinatol 2007 Sep;24(8):449-456.

48. Zidere V, Bellsham-Revell H, Persico N, Allan LD. Comparison of echocardiographic findings in fetuses at less than 15 weeks' gestation with later cardiac evaluation. Ultrasound Obstet Gynecol 2013 Dec;42(6):679-686.

49. Clur SA, Bilardo CM. Early detection of fetal cardiac abnormalities: how effective is it and how should we manage these patients? Prenat Diagn 2014 Dec;34(13):1235-1245. 
50. Pike JI, Krishnan A, Donofrio MT. Early fetal echocardiography: congenital heart disease detection and diagnostic accuracy in the hands of an experienced fetal cardiology program. Prenat Diagn 2014 Aug;34(8):790-796.

51. Mogra R, Saaid R, Kesby G, Hayward J, Malkoun J, Hyett J. Early fetal echocardiography: experience of a tertiary diagnostic service. Aust N Z J Obstet Gynaecol 2015 Dec;55(6):552-558.

52. Ventriglia F, Caiaro A, Giancotti A, Abed MM, Ceccacci I, Celani S, Vitiello L, Colloridi F, Messina E. Reliability of early fetal echocardiography for congenital heart disease detection: a preliminary experience and outcome analysis of 102 fetuses to demonstrate the value of a clinical flow-chart designed for at-risk pregnancy management. Pediat Therapeut 2016;6:270.

53. Khalil A, Nicolaides KH. Fetal heart defects: potential and pitfalls of first-trimester detection. Semin Fetal Neonatal Med 2013 Oct;18(5):251-260.

54. Llurba E, Syngelaki A, Sánchez O, Carreras E, Cabero L, Nicolaides KH. Maternal serum placental growth factor at 11-13 weeks' gestation and fetal cardiac defects. Ultrasound Obstet Gynecol 2013 Aug;42(2):169-174.

55. Llurba E, Sánchez O, Ferrer Q, Nicolaides KH, Ruíz A, Domínguez C, Sánchez-de-Toledo J, García-García B, Soro G, Arévalo S, et al. Maternal and foetal angiogenic imbalance in congenital heart defects. Eur Heart J 2014 Mar;35(11):701-707.

56. Sánchez O, Domínguez C, Ruiz A, Ribera I, Alijotas J, Cabero L, Carreras E, Llurba E. Angiogenic gene expression in down syndrome fetal hearts. Fetal Diagn Ther 2016;40(1):21-27.
57. Jelliffe-Pawlowski L, Baer R, Moon-Grady AJ, Currier RJ. Second trimester serum predictors of congenital heart defects in pregnancies without chromosomal or neural tube defects. Prenat Diagn 2011 May;31(5):466-472.

58. Votino C, Cos T, Abu-Rustum R, Dahman Saidi S, Gallo V, Dobrescu O, Dessy H, Jani J. Use of spatiotemporal image correlation at 11-14 weeks' gestation. Ultrasound Obstet Gynecol 2013 Dec;42(6):669-678.

59. Espinoza J, Lee W, Viñals F, Martinez JM, Bennasar M, Rizzo G, Belfort M. Collaborative study of 4-dimensional fetal echocardiography in the first trimester of pregnancy. J Ultrasound Med 2014 Jun;33(6):1079-1084.

60. Viñals F, Ascenzo R, Naveas R, Huggon I, Giuliano A. Fetal echocardiography at $11+0$ to $13+6$ weeks using fourdimensional spatiotemporal image correlation telemedicine via an Internet link: a pilot study. Ultrasound Obstet Gynecol 2008 Jun;31(6):633-638.

61. Bennasar M, Martínez JM, Olivella A, del Río M, Gómez O, Figueras F, Puerto B, Gratacós E. Feasibility and accuracy of fetal echocardiography using four-dimensional spatiotemporal image correlation technology before 16 weeks' gestation. Ultrasound Obstet Gynecol 2009 Jun;33(6):645-651.

62. Yeo L, Romero R. Fetal Intelligent Navigation Echocardiography (FINE): a novel method for rapid, simple, and automatic examination of the fetal heart. Ultrasound Obstet Gynecol 2013 Sep;42(3):268-284. 